\title{
Identifying Risk Factors for Healthcare-Associated Infections Caused by Carbapenem-Resistant Acinetobacter baumannii in a Neonatal Intensive Care Unit
}

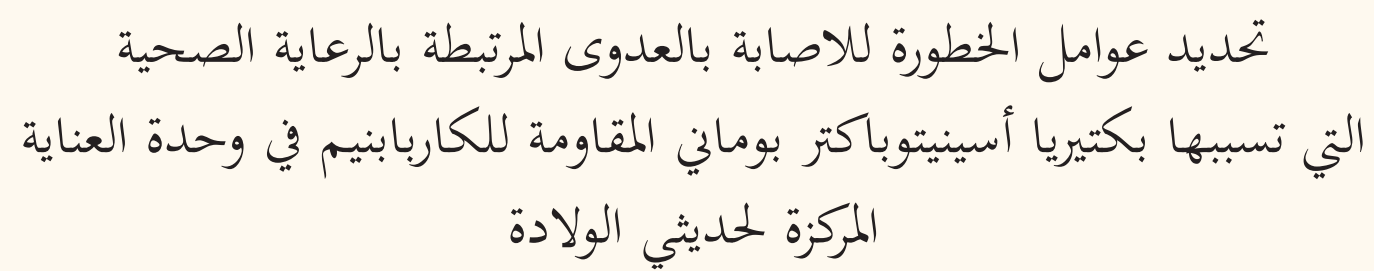

أميرة محمد سلطان و وائل سليم

ABSTRACT: Objectives: Acinetobacter baumannii is a causative pathogen of various healthcare-associated infections (HAIs) and is particularly prevalent in high-risk hospital settings. This study aimed to determine risk factors associated with HAIs caused by carbapenem-resistant $A$. baumannii (CRAB) in a neonatal intensive care unit (NICU). Methods: This prospective study was performed between January 2013 and June 2014 among NICU patients at the Mansoura University Children's Hospital, Mansoura, Egypt. Neonates who developed HAIs due to CRAB were assigned to a case group, while those infected with carbapenem-sensitive A. baumannii (CSAB) were assigned to a control group. Results: Among the 124 neonates who developed A. baumannii-caused HAIs during the study period, 91 (73.4\%) were caused by CRAB and 33 (26.6\%) were caused by CSAB. Prematurity, premature rupture of the membranes (PROM), a previous stay in another hospital, prolonged NICU stay, the presence of invasive devices, previous exposure to carbapenems or aminoglycosides and prolonged antibiotic therapy before infection were significantly associated with CRAB-caused HAIs. A multivariate logistic regression analysis identified prematurity (adjusted odds ratio $[\mathrm{aOR}]=25.3 ; P<0.01)$, mechanical ventilation $(\mathrm{aOR}=18.9 ; P<0.01)$ and the previous use of carbapenems $(\mathrm{aOR}=124.7 ; P<0.01)$ or aminoglycosides $(\mathrm{aOR}=22.6 ; \mathrm{P}=0.04)$ to be independent risk factors for CRAB infections. Conclusion: Various risk factors were significantly associated with CRAB-caused HAIs among the studied NICU patients.

Keywords: Healthcare Associated Infections; Antimicrobial Drug Resistance; Carbapenem Antibiotics; Acinetobacter baumannii; Neonatal Intensive Care Units; Egypt.

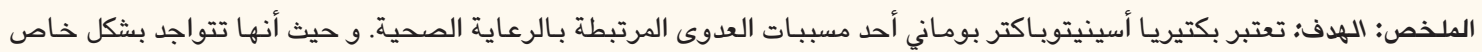

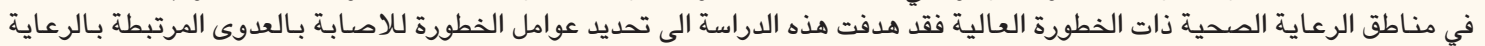

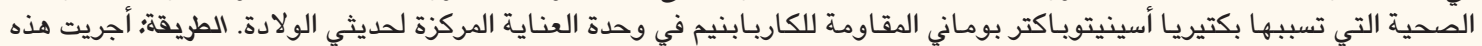

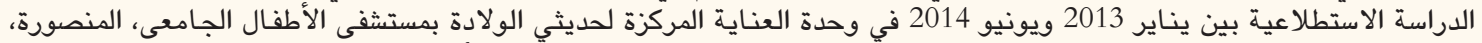

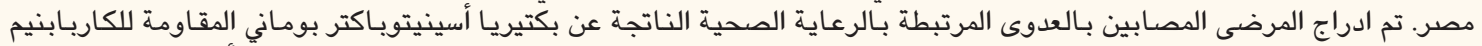

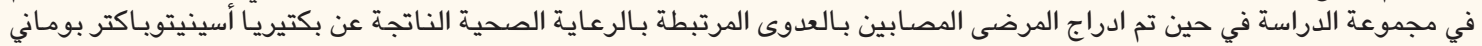

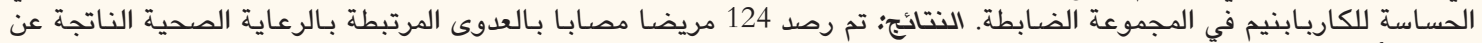

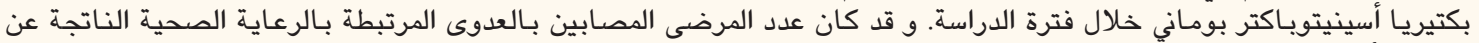

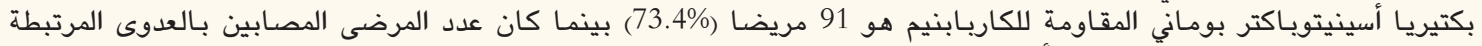

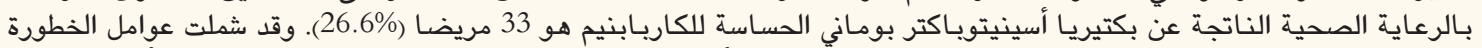

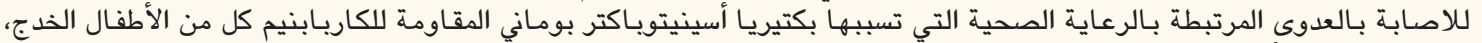

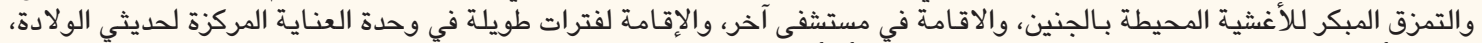

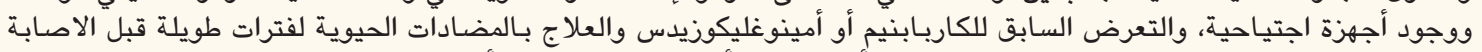

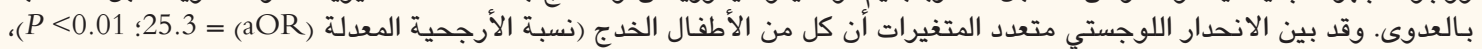

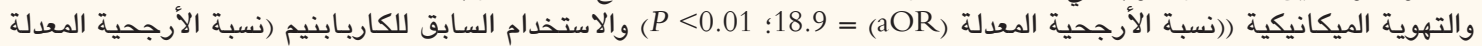
ل) (aOR)

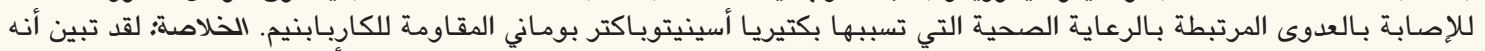

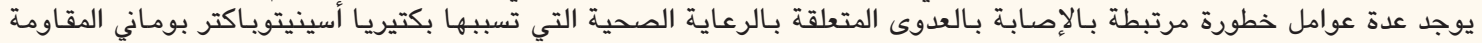

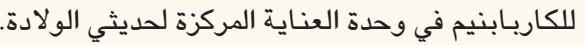

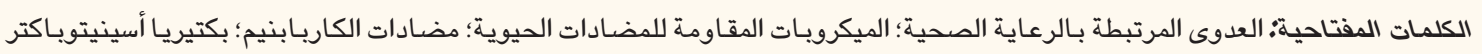
بوماني؛ وحدة العناية المركزة لعديثي الولادة؛ مصركة 


\section{AdVANCES IN KNOWLEDGE}

The current study identified significant risk factors associated with healthcare-associated infections (HAIs) caused by carbapenemresistant Acinetobacter baumannii (CRAB) among patients in a neonatal intensive care unit (NICU) in Egypt.

Significant risk factors included prematurity, premature rupture of the membranes, a previous stay in another hospital, prolonged NICU stay, the presence of an invasive device (i.e. an umbilical catheter, urinary catheter or mechanical ventilator), previous exposure to carbapenems or aminoglycosides and prolonged antibiotic therapy prior to the infection.

application to Patient Care

The findings of this study may be utilised by NICU staff to decrease risk factors associated with carbapenem resistance among Egyptian neonates.

\section{$\mathrm{H}$} EALTHCARE-ASSOCIATED INFECTIONS (HAIs) are infections contracted in various healthcare settings and are well known to increase morbidity, mortality, length of hospital stay and the cost of medical care. ${ }^{1}$ Intensive care units (ICUs), including neonatal ICUs (NICUs), constitute high-risk areas for HAIs as admitted patients are usually critically ill and commonly undergo invasive procedures. ${ }^{2}$ Acinetobacter baumannii is a major causative pathogen of various HAIs, such as bloodstream infections and pneumonia, particularly in high-risk settings such as ICUs. Unfortunately, recent studies have reported a steady increase in the prevalence of carbapenemresistant $A$. baumannii (CRAB) strains isolated from patients with HAIs. ${ }^{3-5}$ This study therefore aimed to determine risk factors for the development of CRABcaused HAIs among patients in a NICU in Egypt.

\section{Methods}

This prospective single-centre study was conducted between January 2013 and June 2014 in the NICU of the Mansoura University Children's Hospital, Mansoura, Egypt. All patients who developed A. baumanniicaused HAIs of any type following their admission to the NICU were included in the study. The identification of $A$. baumannii strains was performed using colony morphology, microscopic examination and biochemical tests. The $\mathrm{API}^{\circledR} 20 \mathrm{NE}$ identification system (bioMérieux Inc, St. Louis, Missouri, USA) was used to confirm the diagnosis of an A. baumanniicaused infection. Patients who developed HAIs with A. baumannii isolates showing resistance to imipenem or meropenem were assigned to a case group while those with isolates sensitive to imipenem and meropenem were assigned to a control group. The sensitivity patterns of the isolated $A$. baumannii strains were detected using the disc diffusion method. All results were interpreted using the guidelines of the Clinical and Laboratory Standards Institute. ${ }^{6}$

Surveillance procedures conducted for patients with different types of HAIs were performed according to the definitions, elements and criteria of the Centers for Disease Control and Prevention. ${ }^{7}$ Infections developing during the first two calendar days of hospital stay were deemed to have been present upon admission, while infections developing on or after the third calendar day of hospital stay were considered HAIs. Information regarding the HAI was collected by reviewing the patients' medical records and their clinical and laboratory findings. Possible risk factors were documented for each patient, including prematurity $(<37$ gestational weeks); low birth weight $(<2,500 \mathrm{~g})$; premature rupture of the membranes; age; gender; previous stay in another hospital; length of NICU stay prior to infection; the presence of an invasive device; duration of antibiotic therapy before the HAI; and previous antibiotic exposure. The latter risk factor was considered present only in cases wherein systemic antibiotics were administered for a minimum of 24 hours within the 14-day period prior to the isolation of the A. baumannii strain. In terms of patient outcome, HAI-related mortality was defined as death within 30 days of developing the infection.

Statistical analysis was performed using the Statistical Package for the Social Sciences (SPSS), Version 22.0 (IBM Corp, Armonk, New York, USA). Nonparametric demographic and clinical parameters were compared using the Mann-Whitney U test and presented as medians and ranges. Categorical variables were compared using the Chi-squared test and presented as percentages. A multivariate analysis was performed using binary logistic regression to assess independent risk factors for CRAB-caused HAIs. Differences were considered statistically significant at $P \leq 0.05$.

Table 1: Healthcare-associated infections caused by carbapenem-resistant or -sensitive Acinetobacter baumannii in a neonatal intensive care unit in Egypt $(\mathrm{N}=124)$

\begin{tabular}{lcc} 
Type of infection & \multicolumn{2}{c}{$\mathbf{n}(\%)$} \\
& $\begin{array}{c}\text { CRAB } \\
(\mathbf{n}=91)\end{array}$ & $\begin{array}{c}\text { CSAB } \\
(\mathbf{n}=33)\end{array}$ \\
Blood stream & $65(71.4)$ & $22(66.7)$ \\
Pneumonia & $17(18.7)$ & $7(21.2)$ \\
Urinary tract & $7(7.7)$ & $3(9.1)$ \\
Other & $2(2.2)$ & $1(3)$
\end{tabular}

$C R A B=$ carbapenem-resistant Acinetobacter baumannii; CSAB = carbapenem-sensitive A. baumannii. 
Table 2: Risk factors associated with healthcare-associated infections caused by carbapenem-resistant or -sensitive Acinetobacter baumannii in a neonatal intensive care unit in Egypt $(\mathrm{N}=124)$

\begin{tabular}{|c|c|c|c|c|c|}
\hline \multirow[t]{2}{*}{ Risk factor } & \multicolumn{3}{|c|}{$\begin{array}{c}\text { Univariate analysis, } \\
\mathbf{n}(\%)\end{array}$} & \multicolumn{2}{|c|}{ Multivariate analysis } \\
\hline & $\begin{array}{l}\text { CRAB } \\
(\mathbf{n}=91)\end{array}$ & $\begin{array}{c}\text { CSAB } \\
(\mathbf{n}=33)\end{array}$ & $P$ value & aOR $(95 \% \mathrm{CI})$ & $P$ value \\
\hline \multicolumn{6}{|l|}{ Postnatal age in days } \\
\hline$<7$ & $45(49.5)$ & $18(54.5)$ & 0.65 & & \\
\hline$\geq 7$ & $46(50.5)$ & $15(45.5)$ & 0.35 & & \\
\hline Male gender & $39(42.9)$ & $16(48.5)$ & 0.78 & & \\
\hline Prematurity & $54(59.3)$ & $8(24.2)$ & $0.03^{*}$ & $25.3(8.4-784.8)$ & $<0.01^{*}$ \\
\hline LBW & 29 (31.9) & $10(30.3)$ & 0.88 & & \\
\hline PROM & $42(46.2)$ & $5(15.2)$ & $0.01^{*}$ & & \\
\hline PSAH & $17(18.7)$ & $2(6.1)$ & $0.03^{*}$ & & \\
\hline $\begin{array}{l}\text { Median length of stay in the NICU } \\
\text { prior to HAI (range) }\end{array}$ & $10(6.4-15.2)$ & $4(2.6-7.9)$ & $0.04^{*}$ & & \\
\hline \multicolumn{6}{|l|}{ Presence of an invasive device } \\
\hline Umbilical catheter & $70(76.9)$ & $11(33.3)$ & $0.04^{*}$ & & \\
\hline PPCL & $10(11)$ & $5(15.2)$ & 0.85 & & \\
\hline Urinary catheter & $66(72.5)$ & $7(21.2)$ & $<0.01^{*}$ & & \\
\hline MV & $72(79.1)$ & $9(27.3)$ & $<0.01^{*}$ & $18.9(3.5-1,135.1)$ & $<0.01^{*}$ \\
\hline \multicolumn{6}{|l|}{ Previous antibiotic exposure } \\
\hline Carbapenems & $55(60.4)$ & $5(15.2)$ & $<0.01^{*}$ & $124.7(45.2-588.1)$ & $<0.01^{*}$ \\
\hline Cephalosporins & $24(26.4)$ & $6(18.2)$ & 0.07 & & \\
\hline Aminoglycosides & $42(46.2)$ & 4. (12.1) & $0.02^{*}$ & $22.6(1.1-864.9)$ & $0.04^{*}$ \\
\hline Vancomycin & $30(33)$ & $12(36.4)$ & 0.79 & & \\
\hline $\begin{array}{l}\text { Median duration of antibiotic } \\
\text { therapy before HAI in days (range) }\end{array}$ & $8(5.7-10.4)$ & $2(1.2-4.6)$ & $<0.05^{*}$ & & \\
\hline
\end{tabular}

$C R A B=$ carbapenem-resistant Acinetobacter baumannii; $C S A B=$ carbapenem-sensitive $A$. baumannii; $a O R=$ adjusted odds ratio; $C I=$ confidence interval; $L B W=$ low birth weight; $P R O M=$ premature rupture of the membranes; $P S A H=$ previous stay in another hospital; $N I C U=$ neonatal intensive care unit; $H A I=$ healthcare-associated infection; $P P C L=$ peripheral percutaneous central line; $M V=$ mechanical ventilator.

"Considered statistically significant at $P \leq 0.05$.

This study received ethical approval from the Institutional Review Board of the Faculty of Medicine, Mansoura University (\#R/17.10.10). Informed consent was obtained from a parent or guardian of all of the patients included in the study.

\section{Results}

During the study period, 124 neonates in the NICU developed HAIs caused by A. baumannii. Of these, 91 infections (73.4\%) were caused by CRAB and 33 (26.6\%) were caused by carbapenem-sensitive $A$. baumannii (CSAB). In both groups, bloodstream infections were most common [Table 1]. There was no statistically significant difference between the groups in terms of sites of infection. Prematurity, premature rupture of the membranes, a previous stay in another hospital and prolonged NICU stay prior to infection were identified as significant risk factors for CRAB-caused HAIs ( $P<0.05$ each). Moreover, the presence of an umbilical catheter, urinary catheter or mechanical ventilator, previous exposure to carbapenems or aminoglycosides and prolonged antibiotic therapy were also significant risk factors $(P<0.05$ each). Prematurity (adjusted odds ratio $[\mathrm{aOR}]=25.3 ; P<0.01)$, mechanical ventilation $(\mathrm{aOR}=18.9 ; \quad P<0.01)$ and the previous use of carbapenems ( $\mathrm{aOR}=124.7 ; P<0.01)$ or aminoglycosides $(\mathrm{aOR}=22.6 ; P=0.04)$ were independent risk factors for CRAB infections [Table 2].

A total of $70(76.9 \%)$ patients with CRAB infections and eight (24.2\%) patients with CSAB infections died; this difference in mortality rate between the two groups was statistically significant $(P=0.01)$. Significant mortality-related risk factors among patients with 
Table 3: Mortality-related risk factors among patients with health-care-associated infections caused by carbapenemresistant or -sensitive Acinetobacter baumannii in a neonatal intensive care unit in Egypt

$(\mathrm{N}=124)$

\begin{tabular}{|c|c|c|c|c|c|}
\hline \multirow[t]{2}{*}{ Variable } & \multicolumn{3}{|c|}{$\begin{array}{l}\text { Univariate analysis, } \\
\text { n (\%) }\end{array}$} & \multicolumn{2}{|c|}{ Multivariate analysis } \\
\hline & $\begin{array}{l}\text { CRAB } \\
(\mathbf{n}=70)\end{array}$ & $\begin{array}{l}\text { CSAB } \\
(\mathbf{n}=8)\end{array}$ & $P$ value & aOR $(95 \% \mathrm{CI})$ & $P$ value \\
\hline \multicolumn{6}{|l|}{ Postnatal age in days } \\
\hline$<7$ & $32(45.7)$ & $3(37.5)$ & 0.38 & & \\
\hline$\geq 7$ & $38(54.3)$ & $5(62.5)$ & 0.61 & & \\
\hline Male gender & $34(48.6)$ & $4(50)$ & 0.80 & & \\
\hline Prematurity & $33(47.1)$ & $3(37.5)$ & 0.21 & & \\
\hline LBW & $25(35.7)$ & $3(37.5)$ & 0.89 & & \\
\hline PROM & $32(45.7)$ & $4(50)$ & 0.42 & & \\
\hline PSAH & $10(14.3)$ & $1(12.5)$ & 0.67 & & \\
\hline $\begin{array}{l}\text { Median length of NICU stay prior to } \\
\text { HAI (range) }\end{array}$ & $12(8.3-15.2)$ & $5.4(3.6-7.9)$ & $0.02^{*}$ & & \\
\hline \multicolumn{6}{|l|}{ Presence of an invasive device } \\
\hline Umbilical catheter & $55(78.6)$ & $1(12.5)$ & $<0.01^{*}$ & & \\
\hline PPCL & $8(11.4)$ & $1(12.5)$ & 0.82 & & \\
\hline Urinary catheter & $54(77.1)$ & $6(75)$ & 0.87 & & \\
\hline MV & $57(81.4)$ & $2(25)$ & $0.02^{*}$ & $17.2(2.1-129.2)$ & $0.04 *$ \\
\hline \multicolumn{6}{|l|}{ Previous antibiotic exposure } \\
\hline Carbapenems & $53(75.7)$ & $1(12.5)$ & $<0.01^{*}$ & $79.1(32.7-278.9)$ & $<0.01^{*}$ \\
\hline Cephalosporins & $18(25.7)$ & $2(25)$ & 0.94 & & \\
\hline Aminoglycosides & $20(28.6)$ & $2(25)$ & 0.76 & & \\
\hline Vancomycin & $25(35.7)$ & $3(37.5)$ & 0.65 & & \\
\hline $\begin{array}{l}\text { Median days of antibiotic therapy } \\
\text { before HAI in days (range) }\end{array}$ & $5.1(3.8-8.7)$ & $3.2(2.1-3.5)$ & 0.09 & & \\
\hline
\end{tabular}

$C R A B=$ carbapenem-resistant Acinetobacter baumannil; $C S A B=$ carbapenem-sensitive $A$. baumannii; aOR = adjusted odds ratio; $C I=$ confidence interval; $L B W=$ low birth weight; $P R O M=$ premature rupture of the membranes; $P S A H=$ previous stay in another hospital; $N I C U=$ neonatal intensive care unit; $H A I=$ healthcare-associated infection; $P P C L=$ peripheral percutaneous central line; $M V=$ mechanical ventilator.

*Considered statistically significant at $P \leq 0.05$.

CRAB infections included prolonged NICU stay, the presence of an umbilical catheter or mechanical ventilator and the previous administration of carbapenems ( $P<0.02$ each). Independent risk factors for mortality were mechanical ventilation $(\mathrm{aOR}=17.2 ; P=0.04)$ and the previous use of carbapenems $(\mathrm{aOR}=79.1 ; P<0.01)$ [Table 3]. Isolates from both the CRAB and CSAB groups demonstrated high resistance rates to all antimicrobials except for tigecycline, with no significant differences between the two groups [Table 4].

\section{Discussion}

The ability to survive in a hospital environment has resulted in a high incidence of HAIs attributed to A. baumannii; furthermore, the organism rapidly deve- lops resistance to a broad range of antibiotic classes. ${ }^{8}$ Previous research has indicated that the incidence of A. baumannii-resistant strains is increasing all over the world. $^{3-5}$ According to surveillance data in the USA, carbapenem resistance increased from $5.2 \%$ to $40.8 \%$ between 1999 and 2010.9 Similarly, in Europe, surveillance data from 2012 indicated that $68.8 \%$ of A. baumannii strains isolated from ICUs were resistant to carbapenems. ${ }^{10}$ These findings support those of the present study which indicated a high rate of carbapenem resistance in the studied Egyptian NICU.

In terms of invasive procedures, mechanical ventilation was the only independent risk factor for CRABcaused HAIs in the current study. Previous studies have reported similar findings. ${ }^{11,12}$ Mechanical ventilation is indicated for neonates in cases of respiratory distress, 
Table 4: Antimicrobial resistance of carbapenem-resistant and -sensitive Acinetobacter baumannii isolates in a neonatal intensive care unit in Egypt $(\mathrm{N}=124)$

\begin{tabular}{|c|c|c|c|}
\hline \multirow[t]{2}{*}{ Antimicrobial } & \multicolumn{2}{|c|}{ n (\%) } & \multirow[t]{2}{*}{$P$ value } \\
\hline & $\begin{array}{l}\text { CRAB } \\
(\mathbf{n}=91)\end{array}$ & $\begin{array}{l}\text { CSAB } \\
(\mathbf{n}=33)\end{array}$ & \\
\hline $\begin{array}{l}\text { Amoxicillin and } \\
\text { clavulanic acid } \\
(30 \mu \mathrm{g} / \mathrm{mL})\end{array}$ & 85 (93.4) & 27 (81.8) & 0.85 \\
\hline $\begin{array}{l}\text { Piperacillin- } \\
\text { tazobactam } \\
(110 \mu \mathrm{g} / \mathrm{mL})\end{array}$ & $80(87.9)$ & $25(75.8)$ & 0.68 \\
\hline $\begin{array}{l}\text { Cefotaxime } \\
(30 \mu \mathrm{g} / \mathrm{mL})\end{array}$ & $91(100)$ & $33(100)$ & $>0.99$ \\
\hline $\begin{array}{l}\text { Cefepime } \\
(30 \mu \mathrm{g} / \mathrm{mL})\end{array}$ & $71(78)$ & $26(78.8)$ & 0.98 \\
\hline $\begin{array}{l}\text { Gentamicin } \\
(10 \mu \mathrm{g} / \mathrm{mL})\end{array}$ & 78 (85.7) & 27 (81.8) & 0.87 \\
\hline $\begin{array}{l}\text { Amikacin } \\
(30 \mu \mathrm{g} / \mathrm{mL})\end{array}$ & 87 (95.6) & 29 (87.9) & 0.69 \\
\hline $\begin{array}{l}\text { Ciprofloxacin } \\
(5 \mu \mathrm{g} / \mathrm{mL})^{*}\end{array}$ & $86(94.5)$ & 27 (81.8) & 0.85 \\
\hline $\begin{array}{l}\text { Tigecycline } \\
(15 \mu \mathrm{g} / \mathrm{mL})\end{array}$ & $9(9.9)$ & 4. (12.1) & 0.58 \\
\hline
\end{tabular}

$C R A B=$ carbapenem-resistant Acinetobacter baumannii; $C S A B=$ carbapenem-sensitive A. baumannii. "Not recommended for use in neonates

hypoxaemia or hypercapnia; however, organisms present in the hospital environment frequently attach to the ventilator tube and form a biofilm which is associated with an increased risk of antibiotic resistance. ${ }^{13}$ Furthermore, ventilated critically-ill neonates often undergo endotracheal intubation which can interrupt immunity barriers. ${ }^{14}$ Therefore, the incidence of HAIs may potentially be reduced by encouraging the use of noninvasive ventilation among neonates, such as nasal continuous positive pressure ventilation. ${ }^{15}$

In the current study, a previous stay in another hospital and prolonged NICU stay prior to infection were found to constitute significant risk factors for subsequent CRAB infections. This may be attributable to prolonged exposure to organisms present in the hospital environment and the extended use of antibiotics that aid in the development of antimicrobial resistance. ${ }^{11,12}$ Rosa et al. reported that exposure to a contaminated hospital environment increased the risk of acquisition of CRAB isolates. ${ }^{16}$ Baran et al. indicated that patients admitted to the ICU had a three-fold higher risk of CRAB infections. ${ }^{17}$ Playford et al. also observed an association between prolonged ICU stay and $C R A B$ infection. ${ }^{18}$ Unfortunately, the nature of multidrug-resistant microorganisms, including A. baumannii, in ICUs is endemic. In addition, the likelihood of antimicrobial therapy increases with the duration of ICU stay, thus leading to the colonisation of resistant strains of bacteria.
Previous exposure to carbapenems was another independent risk factor for HAIs caused by CRAB in the present study. Sheng et al. also noted that patients with CRAB infections were significantly more likely to have been exposed to carbapenems. ${ }^{19}$ Such findings emphasise the need for the judicious use of carbapenem antibiotics, which should remain a last resort in the treatment of serious infections so as to control the development of carbapenem-resistant microbes. As with carbapenems, previous exposure to aminoglycosides was another independent risk factor for CRAB infections in the current study. Chen et al. also observed prior exposure to aminoglycosides such as amikacin to be a risk factor for CRAB. ${ }^{20}$ Treating physicians should therefore consider these findings before prescribing aminoglycosides to ICU patients.

In the current study, CRAB isolates showed high resistance rates to other antibiotics. Similar findings were reported by Falagas et al. among pandrug-resistant A. baumannii infection cases. ${ }^{21}$ Infections caused by multidrug-resistant pathogens have many adverse outcomes, including prolonged hospital stay, higher treatment costs and increased mortality rates. ${ }^{22}$ The treatment of patients suffering from infections caused by such strains is challenging. Adequate knowledge of local $A$. baumannii resistance patterns is a fundamental element to a successful therapeutic approach. ${ }^{23}$ In terms of mortality, the presence of an umbilical catheter or mechanical ventilator, prolonged stay in the NICU and the previous administration of carbapenems resulted in significantly increased mortality among patients with HAIs caused by CRAB. Similar results were reported by Djordjevic et al. among adult patients admitted to a medical-surgical ICU. ${ }^{24}$

This study is subject to certain limitations. Generally, NICUs in developing countries such as Egypt usually have low staff-to-patient ratios, often resulting in a lack of essential infection control precautions like thorough hand hygiene and aseptic procedures. Under these conditions, resistant bacteria can more easily spread between patients, resulting in more colonised and infected cases compared to adequately staffed units. In addition, the low number of patients in the control group in comparison to the case group resulted in a wide confidence interval, weakening the findings of the present study.

\section{Conclusion}

This study found that prematurity, premature rupture of the membranes, a previous stay in another hospital, prolonged NICU stay, the presence of an invasive device, previous exposure to carbapenems or aminoglycosides and prolonged antibiotic therapy were signif- 
icantly associated with CRAB-caused HAIs in an NICU in Egypt. Moreover, prematurity, mechanical ventilation and previous exposure to carbapenems or aminoglycosides were independent risk factors for the development of HAIs caused by CRAB.

\section{ACKNOWLEDGEMENTS}

The authors wish to acknowledge the consistent and helpful support of the nursing staff at the Mansoura University Children's Hospital in their provision of professional care to the subjects and implementation of proper research protocols during the study period.

\section{CONFLICT OF INTEREST}

The authors declare no conflicts of interest.

\section{FUNDING}

No funding was received for this study.

\section{References}

1. Sydnor ER, Perl TM. Hospital epidemiology and infection control in acute-care settings. Clin Microbiol Rev 2011; 24:141-73. doi: 10.1128/CMR.00027-10.

2. Mesiano ER, Merchán-Hamann E. Bloodstream infections among patients using central venous catheters in intensive care units. Rev Lat Am Enfermagem 2007; 15:453-9. doi: 10.1590/ S0104-11692007000300014.

3. Sopirala MM, Mangino JE, Gebreyes WA, Biller B, Bannerman T, Balada-Llasat JM, et al. Synergy testing by Etest, microdilution checkerboard, and time-kill methods for pan-drug-resistant Acinetobacter baumannii. Antimicrob Agents Chemother 2010; 54:4678-83. doi: 10.1128/AAC.00497-10.

4. Jung JY, Park MS, Kim SE, Park BH, Son JY, Kim EY, et al. Risk factors for multi-drug resistant Acinetobacter baumannii bacteremia in patients with colonization in the intensive care unit. BMC Infect Dis 2010; 10:228. doi: 10.1186/1471-2334-10228

5. Chuang YC, Cheng CY, Sheng WH, Sun HY, Wang JT, Chen YC, et al. Effectiveness of tigecycline-based versus colistin-based therapy for treatment of pneumonia caused by multidrugresistant Acinetobacter baumannii in a critical setting: A matched cohort analysis. BMC Infect Dis 2014; 14:102. doi: 10.11 86/1471-2334-14-102.

6. Clinical and Laboratory Standard Institute. Performance standards for antimicrobial susceptibility testing, Version M100-S22. Wayne, Pennsylvania, USA: Clinical and Laboratory Standard Institute, 2012

7. Horan TC, Andrus M, Dudeck MA. CDC/NHSN surveillance definition of health care-associated infection and criteria for specific types of infections in the acute care setting. Am J Infect Control 2008; 36:309-32. doi: 10.1016/j.ajic.2008.03.002.

8. Karageorgopoulos DE, Falagas ME. Current control and treatment of multidrug-resistant Acinetobacter baumannii infections. Lancet Infect Dis 2008; 8:751-62. doi: 10.1016/S1473-3099(08) 70279-2.

9. Adams-Haduch JM, Onuoha EO, Bogdanovich T, Tian GB, Marschall J, Urban CM, et al. Molecular epidemiology of carbapenem-nonsusceptible Acinetobacter baumannii in the United States. J Clin Microbiol 2011; 49:3849-54. doi: 10.1128/ JCM.00619-11.
10. European Centre for Disease Prevention and Control. Surveillance report: Annual epidemiological report - antimicrobial resistance and healthcare-associated infections 2014. From: http://ecdc.europa.eu/en/publications/Publications/anti microbial-resistance-annual-epidemiological-report.pdf Accessed: Dec 2017.

11. Dizbay M, Tunccan OG, Sezer BE, Hizel K. Nosocomial imipenem-resistant Acinetobacter baumannii infections: Epidemiology and risk factors. Scand J Infect Dis 2010; 42:741-6. doi: $10.3109 / 00365548.2010 .489568$

12. Vaze ND, Emery CL, Hamilton RJ, Brooks AD, Joshi SG. Patient demographics and characteristics of infection with carbapenem-resistant Acinetobacter baumannii in a teaching hospital from the United States. Adv Infect Dis 2013; 3:10-16. doi: 10.4236/aid.2013.31002.

13. Gil-Perotin S, Ramirez P, Marti V, Sahuquillo JM, Gonzalez E, Calleja I, et al. Implications of endotracheal tube biofilm in ventilator-associated pneumonia response: A state of concept. Crit Care 2012; 16:R93. doi: 10.1186/cc11357.

14. Foglia E, Meier MD, Elward A. Ventilator-associated pneumonia in neonatal and pediatric intensive care unit patients. Clin Microbiol Rev 2007; 20:409-25. doi: 10.1128/CMR.00041-06.

15. Hentschel J, Brüngger B, Stüdi K, Mühlemann K. Prospective surveillance of nosocomial infections in a Swiss NICU: Low risk of pneumonia on nasal continuous positive airway pressure? Infection 2005; 33:350-5. doi: 10.1007/s15010-005-5052-x.

16. Rosa R, Arheart KL, Depascale D, Cleary T, Kett DH, Namias N, et al. Environmental exposure to carbapenem-resistant Acinetobacter baumannii as a risk factor for patient acquisition of A. baumannii. Infect Control Hosp Epidemiol 2014; 35:430-3. doi: $10.1086 / 675601$.

17. Baran G, Erbay A, Bodur H, Ongürü P, Akinci E, Balaban N, et al. Risk factors for nosocomial imipenem-resistant Acinetobacter baumannii infections. Int J Infect Dis 2008; 12:16-21. doi: 10.1016/j.ijid.2007.03.005

18. Playford EG, Craig JC, Iredell JR. Carbapenem-resistant Acinetobacter baumannii in intensive care unit patients: Risk factors for acquisition, infection and their consequences. J Hosp Infect 2007; 65:204-11. doi: 10.1016/j.jhin.2006.11.010.

19. Sheng $\mathrm{WH}$, Liao $\mathrm{CH}$, Lauderdale $\mathrm{TL}, \mathrm{Ko} W C$, Chen $\mathrm{YS}$, Liu JW, et al. A multicenter study of risk factors and outcome of hospitalized patients with infections due to carbapenemresistant Acinetobacter baumannii. Int J Infect Dis 2010; 14:e764-9. doi: 10.1016/j.ijid.2010.02.2254.

20. Chen YH, Chiueh CC, Lee YJ. Risk factors of carbapenemresistant Acinetobacter baumannii infection among hospitalized patients. J Exp Clin Med 2014; 6:143-6. doi: 10.1016/j. jecm.2014.06.003.

21. Falagas ME, Rafailidis PI, Matthaiou DK, Virtzili S, Nikita D, Michalopoulos A. Pandrug-resistant Klebsiella pneumoniae, Pseudomonas aeruginosa and Acinetobacter baumannii infections: Characteristics and outcome in a series of 28 patients. Int J Antimicrob Agents 2008; 32:450-4. doi: 10.1016/j.ijanti micag.2008.05.016

22. Young LS, Sabel AL, Price CS. Epidemiologic, clinical, and economic evaluation of an outbreak of clonal multidrug-resistant Acinetobacter baumannii infection in a surgical intensive care unit. Infect Control Hosp Epidemiol 2007; 28:1247-54. doi: $10.1086 / 521660$

23. Michalopoulos A, Falagas ME. Treatment of Acinetobacter infections. Expert Opin Pharmacother 2010; 11:779-88. doi: $10.1517 / 14656561003596350$

24. Djordjevic ZM, Folic MM, Folic ND, Gajovic N, Gajovic O, Jankovic SM. Risk factors for hospital infections caused by carbapanem-resistant Acinetobacter baumannii. J Infect Dev Ctries 2016; 10:1073-80. doi: 10.3855/jidc.8231. 